\title{
Healthy Living for Elders: High Blood Pressure ${ }^{1}$
}

\section{Leigh Ann Martin²}

\section{What is high blood pressure?}

High blood pressure is increased pressure of blood on the blood vessels. This creates more work for the heart. Another name for high blood pressure is hypertension. About 50 million Americans may have hypertension. Many are not even aware they have a problem.

\section{Hypertension can cause:}

- Atherosclerosis (narrowing and hardening of blood vessels)

$\checkmark$ Heart attack

$\checkmark$ Stroke

$\checkmark$ Kidney failure

$\checkmark$ Damage to the eyes

\section{Am I at risk?}

You are at higher risk of developing hypertension if you:

$\checkmark$ are African American

- are a man

$\checkmark$ are 45 years of age or older

$\checkmark$ eat a high salt diet

$\checkmark$ are overweight

$\checkmark$ had a parent with hypertension

$\checkmark$ drink large amounts of alcohol

$\checkmark$ are not physically active
Take A Closer Look:

Healthy Artery

Artery with Atherosclerosis

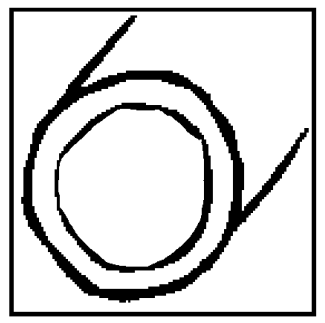

Blood flows freely.

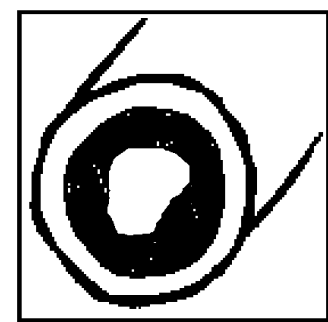

Blood flows under higher pressure.

\section{Check Your Blood Pressure:}

Regular blood pressure check-ups help your doctor detect or monitor hypertension. Have your blood pressure checked by a health professional at least once a year. The ENAFS "Keep Track of Your Blood Pressure” log can help you monitor your blood pressure in between doctors visits.

1. This document, FCS8599-Eng, is one in a series of the Department of Family, Youth and Community Sciences, Florida Cooperative Extension Service, Institute of Food and Agricultural Sciences, University of Florida, Gainesville, FL 32611. Publication date: March 2004. This leaflet was developed with funding from the Florida Department of Elder Affairs in partnership with state, county, and local agencies. Please visit the EDIS Web site at http://edis.ufl.edu

2. Leigh Ann Martin, MESS., former ENAFS project coordinator, Department of Family, Youth and Community Sciences, Institute of Food and Agricultural Sciences, University of Florida, Gainesville, FL 32611. Reviewed by Linda B. Bobroff, PhD, RD, LD/N, professor, University of Florida 